\title{
Study For Water Shutoff Using Tandem Through Tubing Bridge Plugs Technique,Case Study
}

\author{
${ }^{1}$ Dr. Ahmed Samer Azab, ${ }^{2}$ Dr. Aly Elsayed Abbas, ${ }^{3}$ Dr. Mohamed Kassab, ${ }^{4}$ Dr. Adel Salem, ${ }^{5}$ Dr. Ayman \\ Hamed \\ *Faculty of Petroleum and Mining Engineering, Suez University, Suez, Egypt \\ ** Petroleum Research Institute, Cairo, Egypt
}

Article History: Received:11 January 2021; Accepted: 27 February 2021; Published online: 5 April 2021

\begin{abstract}
Increasing water production rate is from one of the well knownmain problems that face any oil producer in the world. Although this problem is most happen in old wells, this can also happen in new drilled wells as well. It causes differenteconomic problems for oil produced companies. First, increasing water production affectsproduced wells performance and reduced their production lifetime. The high percentage of the water in the wellbore increasing the hydrostatic pressure (weight of the fluid column) which cause increasing in the lifting power required. which increasingoil and gas production cost per barrel and causing toreduce the drawdown. As an example, if the well is gas lift well, the quantity of gas needs to be injected for lifting the fluid from the wellbore to the surface is increasing with the production of heigh water cut than without producing water. Increasing water cut percentage and Water production also increases the possibility of corrosion, scale and has negative effect on the field equipment starting from the wellbore itself to the surface facilities. Also another serious and important problem is increasing produced water separating cost, treatment, and disposal is a great challenge to oil producers budgets. It costs almost $\$ 1.1$ billion/year in averageforseparation and disposal of the produced water. Found solution for that type of production help in minimizingcost for the operators and increasing the yearly profit of their operations. Then, water shutoff jobs and operations are very essential. Finally, bythe good understandingfor the formation characterizations and otherfield problems of the field, we can avoid un-necessary water production during the wellbore designing stage.Through tubing bridge plugs (TTBPs) as one of water shut-off (WSO) workovers in the Belayim Fields resulted in average gradualproduction increasing of 2450 bopd.The Average water cut percentage (WC) reduced from 54\% to $15 \%$. 87 WSOworkoversjobs done since December 1991. Technical evaluation and economical income successful evaluation approaches $90 \%$. Just below 4.5 million dollars companies spent for an average cost of 60,500 dollars per job. Costs spent in less than two days equal to using income from a13 dollars per barrel from crude oil price. Depend on achieved results during the last 4.5 years, these WSO (water shut off)workoversdone in Belyim Field as an effective and on-going cases history for running and set zone water production control. Water production probleminBelayim Field gradually increasing during the last 10 years. Which result indropping inoil production rates.Depend on the reservoir characteristics; lower water zone isolated using through tubing bridge plugs (TTBPs)usingSchlumberegerelectric line units. Dump bailer tools used to put a 14 feet cement cap above the TTBPs to have means of a permanent pressure seal. After 24-hourswaiting on cement time, wells returned back to production with a great change and higher oil rate and very good reduction in Water Cut. Rigless cost for TTBP water shut off workover becomes much less than conventional rig water shut offoperations which result in averaged more than 450,000 dollars per job. Before December 1990, conventional rig operationsWSOwasonly the method used in Belayim Field. now, riglessWSOworkovers becomesa very important for reducing cost or to control cost with financial language. RiglessWSOoperations becomes alsovery important reservoir control tool forincreasing oil production and reducing water production which helps to save reservoir energy.
\end{abstract}

\section{Introduction}

Belayim marine oil Field is offshore field in Gulf of Suez (GOS) areaaround $400 \mathrm{~km}$ southeast of Cairo the capital of EgyptThe field location is longitude $32^{\circ} 10^{\prime}$ and $34^{\circ}$ East and latitude $27^{\circ}$ and $30^{\circ}$ North (Robson 1971) andhave orientation a north-northwest-south-southeast. It has very goodoil and gas reserves, with the probable sedimentary basin area measuring around $3500 \mathrm{~km} 2$, and considered as the biggest production oil field in Egypt, (Figure 1). Belayim Field area is the biggestoil producer field in the GOS area; The (OOIP) original oil in place for all fields approached 11 billion barrels by 1995. Production from Belayim Fields during 1995 was 151,000 BOPD. OOIP for Belayim Fields was close to be 2.5 billion barrels by 1996. Recovery from 1978 through 1995 was 740 million barrels of oil. The main and biggest producing formation in Belayim Field is the massive carboniferous Nubian sandstone which has active edge water drive. As a result, over $90 \%$ of TTBP's installed in Nubia wells. WSO case history examples cited in this paper demonstrate an easy and inexpensive reservoir management tool that will helps Petrobel to achieve its expected ultimate recovery target. 


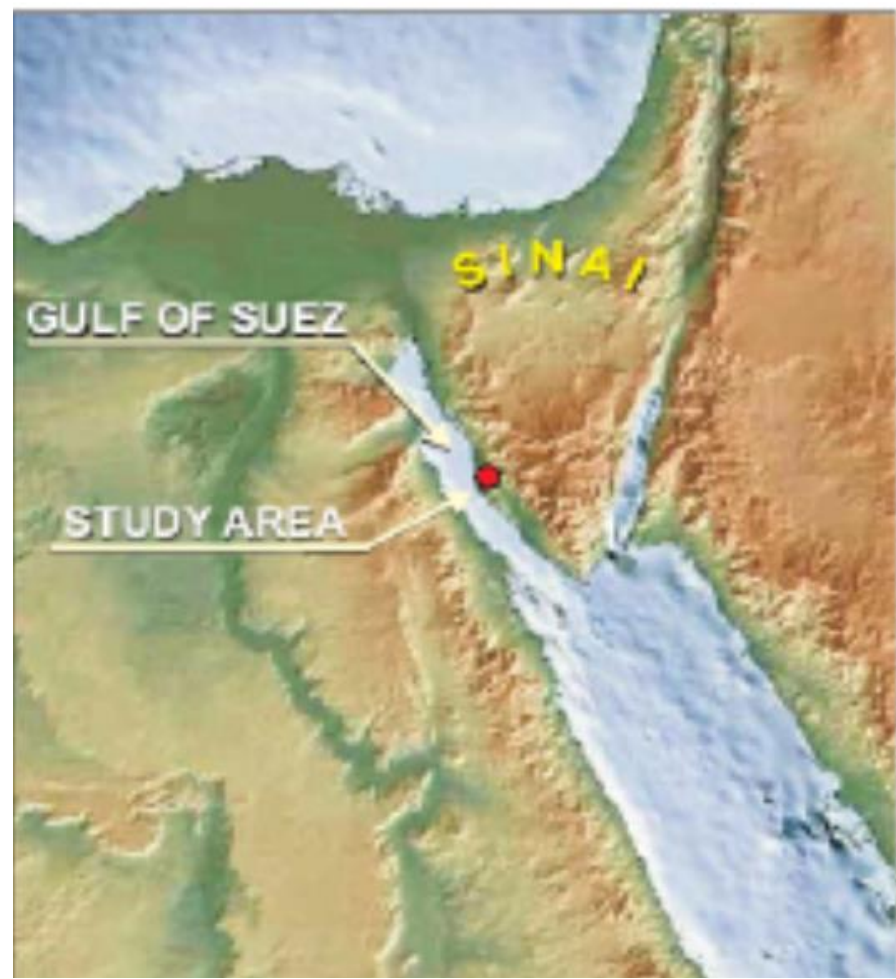

Figure (1) GOS fields map

\section{Field History and Development}

Belayim Field main production formation is Nubia formation, it was discovered during May 1977 after drilling GS-195-1. After two years, a production platform was installed and its associated offshore facilities and the well put on natural flow production. Rate stabilized at 22,500 BOPD and 1 BWPD. Fluid was produced to on-shore facilities at Abu Rudies production stations. Four more wells and a second production platform were added by late 1980 for a combined production rate of 80,000 BOPD and 200 BWPD. The initial (original)pressure for Nubian reservoir was 5400 psig and reduced to 5000 psig after 2 years. By mid-1985, 20 wells were producing from five satellite platforms. BelayimField production exceeded 100,000 bopd with a $3.2 \%$ WC. The 3900 psig reservoir pressure are notenough to give high natural flow rates. Afterone year, average WC reached $12.5 \%$ and production was 125,000 BOPD. Belayim Fields drilling activity continued during the late 1980 'SI and has sharp increasein 1990. Then, a 175,000 BOPD peak in production rate was achieved by the end of 1990. Also drilling is continued in 1990's. which result in, more three producing horizons discovered and developed: Nukhul, Nezzazat2, and Asl formations. By early 1996, Belayim Field had 62 producing wells on nine satellite platforms. Primary production from the main Nubian formation during the last 16 years was attributed to an edge water drive mechanism. underground water enter formation from east and laterally moves through formation layers at different speeds and sweeping oil to west. There is edge water drive only in Nubian formation. No bottom water rise exists 3. The support from Edge water aquifer is limited because reservoir pressure reduced from 5400 to less than 2000 psig; or about 200 psig per year. Production during early 1996 was 186,000 bfpd with a $19 \%$ water cut; or 151,000 bopd and 35,500 bwpd. most Nubia wells now lift from a 0.5inch bottom orifice valve between 8000 and 9800 feet true vertical depth (TVD). One well in the Asl area and two wells in Nezzazat have enough high reservoir pressure for natural flow. Two wells from Nukhul are jet pump using oil lift. Nubia water injection was recently initiated to compensate reservoir pressure decline in some areas.

\section{Geological and Reservoir Properties}

The main Nubian reservoir in Belayim Fields is large oil wet sand which has an average mid zone TVD datum of $-11,250$ feet subsea (SS). Normal fault divided Belayim field to separate areas. The center part from Nubian elongated 6 miles from northwest to southeast. Bounded on the southern and western sides by a big fault. The geological structure becomes complicated by a number of small parallel separate faults. Dip of the formation to the northeast direction at ten 
degrees. Nubia formation has five different sand layers classified as the TZ, MN, M-1, M-2A, and M2B. Everylayer is separated by continuous shale, and almost all sands have shale or low permeability barriers which are relatively discontinuous and thin.A thicker more massive shale, called the layer M-2, is continuous across BelayimField and do as the reference for datum. Also continuous across the field is a heavy oil layer with a stocktankgravityof $13^{\circ}$ API.

This oil layer is 145 feet thick and has an average TVD of -11,400 feet SS. The same for the heavy oil layer separates the TZ, MN, and M-l light oil with a stock tank gravity of $26^{\circ}$ API from water below. The original oil water contact was at -11,660 feet SS. WSO work explained in this paper focuses on the MN, TZ, and M-1 light oil sand layers (Table 1). The layers have 523 feet gross thickness and net pay thickness 480 feet. The average porosity is $16 \%$ in net pay with average permeability of $260 \mathrm{md}$. The permeability increases with depth and ranges from below $200 \mathrm{md}$ in the TZ sand to a more than $1000 \mathrm{md}$ in the M-1. Just the high permeability sand layers are deeper, edge water movements causing the bottom zones to water out first; i.e. the M1 followed by the MN and then the $\mathrm{TZ}$ in final. This characteristic controlling time of WSO job.The produced Unwanted water sources shut off selectively from down sourcesto up. New completions take this into consideration and tubing conveyed perforations are spaced so any future WSO operations can be easily completed.

Table (1) Belayim field Nubian formation general information

\begin{tabular}{|l|c|}
\hline Reservoir temp F & 265 \\
Light crude gravity API & 26.7 \\
Lithology & sandstone \\
Bubble point pressure psi @ datum & 1683 \\
Current reservoir pressure psi @ datum & 2000 \\
Original B , reservoir bbl/stb & 1.1903 \\
Crude viscosity C & 1.0780 \\
Original GOR, scf/stb & 279 \\
Original pressure PSI @ datum & 5506 \\
Gross thickness, feet & 525 \\
Net pay thickness, feet & 488 \\
wettability & Oil wet \\
Average porosity, \% & 16 \\
Average permeability, md & 236 \\
Original oil water contact, feet SS & -11670 \\
\hline
\end{tabular}

\section{WSO wells Selection}

Timing of Water Shut Off work is critical to increase oil production from wells approaching a watered-out condition. Constant allocation of water injection is necessary to maximize field production. Weekly evaluation did for Data from all 62 produced wells in Field to determine appropriate timing of WSO work. Essential data in the on-going monitoring process includes regular evaluation of wellhead conditions, produced fluid WC, production logging tool (PLT) data, well tests, and structural position. There are no standalone criteria for candidate selection. Each carries equal weight for decision making. The following five subheadings describe each data set.

\section{WaterCut}

WC data is collected and recorded in regular basis as required on a weekly or monthly basis depending upon wellhead conditions. Once wellhead temperature begins to rise and lift gas increased, frequency of wellhead we sampling also increases. Experience shows it may only take a few weeks or months before we reach a 30\%, 40\%, or greater level. In case big numbers of wells produce with a high WC, gas lift volume can cause gas lift problems across the field. Hence, if WC is not controlled Field's oil production rate declines.

\section{Well Testing}

Two-phase separator well tests did periodically for Belayim Field producers are infrequent with an average of one test per well every four months. Frequency is low because of increasing well number. Test lines used to reduce back pressure on production lines so maximizing producing rates. Even with infrequent well tests, the steady reservoir pressure declineswith 200 psi per year allows to planthe trend of produced fluids to have accepted estimation of production before a WSO workover. If a well test is not obtained after completing a WSO, a computer model (nodal analysis model) and measured used for post estimatationforworkover production rate until a separator test is obtained. 
Multi-phase flow meter testing was recently initiated in the Belayim Field to help improvingwell test timing and frequency.

\section{WSO OperationProcedure}

In general, the implementation of any producing well water control program is field selective and candidate specific. Properties for Nubia reservoir are such that wellbore isolation only was necessary to control lower zone water production. Also, because of the high permeability contrast between the three light oil layers, the MN and TZ generally do not contribute to the total production stream if the M-1 is open. So, nearly $60 \%$ of Nubia WSO work to date completed to isolate the M-l. electric line units (wire line units) and through-tubing tools keep jobs at a very low almost $\$ 61,500$ average cost as opposed to rig deployed conventional cement squeeze work with an average cost of over $\$ 500,000$ (Table 2). rig deployed WSO work was the only method used in the Field. Therefore, at $12 \%$ of the cost, now rigless water shut off workoversbecomes vital to control the cost in this maturing field. When a rigless TTBP WSO achieved the required result, un presence of a vertical permeability barrier was usually the cause of failure. TTBP set in long perforation interval best illustrates a WSO failure. A few failures were caused by the TTBP element, poor cement behind the casing or poor cement cap. The following four subheadings further describe the role of wellbore preparation, TTBP design, TTBP placement and cement cap design.

Table(2) WSO workoverresult for Belayim field-2006

\begin{tabular}{|c|c|c|c|}
\hline Well no. & date & cost (US \$) & Gain (BOPD) \\
\hline X-2 & May-06 & 550000 & 425 \\
\hline X-3 & May-06 & 140000 & 155 \\
\hline X-4 & June-06 & 230000 & 285 \\
\hline X-5 & July-06 & 320000 & 50 \\
\hline X-6 & Nov.-06 & 400000 & 220 \\
\hline
\end{tabular}

\section{Wellbore Preparation}

Calcium carbonate scale is common in nearly all Nubia wells. Therefore, before running a TTBP, complete tubing gauging is performed. A dummy tool is also run to simulate the TTBP. The dummy is a modified joint of 2.375 inch tubing that approximates the length and stiffness of the TTBP assembly. If tubing obstructions are located, the TTBP cannot be run. Therefore, chemical tubing cleanings are occasionally performed using properly inhibited $15 \% \mathrm{HCL}$ to remove the obstruction.

\section{TTBP Design}

Both retrievable and permanent and TTBP's used to complete WSO work. A 2.5 inch OD tool used for both 5 and 7 inch casing sizes. The tool length ranges between 43 to 57 inches and weighs 200 Ibs (Figure 8). The TTBP is drillable and has a 1500 psi differential rating in both directions. While both Baker and Schlumberger TTBP's have been used for the studied Field WSO work, more than 90\% of the TTBP were purchased from Schlumberger . 


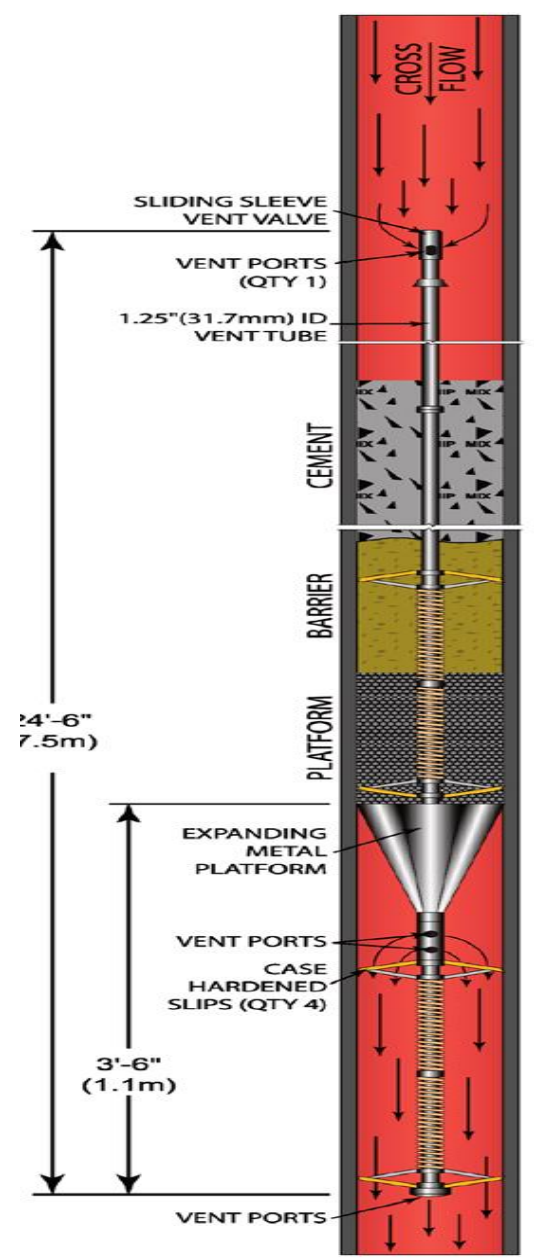

Figure (2) TTBP design and running procedure

\section{9. $\quad$ TTBP Placement}

Limited speedused while running with TTBP in the well so the compressed rubber packer element is not damaged while passing through tubing collars, cross-overs and nipples. The element expands with temperature. Also, high care must be used during a miss-run. To date, only a few TTBPs have become stuck in a completion string. The most common place to stick is in the 3.5 inch tubing or mandrel. Nubia completion string are modified large bore made from 5.5 by 4.5 by 3.5 inch tubing and mandrels. Just setting TTBP, it provides a platform to dump bail cement which becomes the permanent pressure barrier seal. Schlumberger engineering suspected that without a cement seal, the $265^{\circ} \mathrm{F}$ BHT would eventually degrade the sealing element. Placement of a TTBP determines how long water will be suppressed after a WSO. In general, the highest WSO success is achieved from applications where a TTBP is set in non-perforated casing between major perforated intervals. These WSO's provide excellent long term results because thick shales and good cement integrity usually exist between the three light oil sand layers. Thinner shales and reduced cement integrity decreases the length of time an interzonal WSO will prevent or reduce water production even if set between perforated intervals. As expected, only short-term success is achieved by a TTBP set within a perforated interval itself.

\section{CementDesign}

Since a permanent WSO seal was determined essential for long term success, all TTBP's are capped with Portland Class-G cement. Cement is mixed with fresh water. Since BHT is average $265^{\circ} \mathrm{F}$, a retarder should be also added to prevent early setting. Both water salinity and temperature were the biggest contributors for under retarded cement that lead to a few early WSO failures. Cement is placed by electric line dump bailer. Calculated for pressure differential, 14 feet cement covers each TTBP. Each cement dump bailer run covers 3.5 feet in clean 7 inch casing, increasing to 5.5 feet in scaly pipe. After completing the final cement dumping, wells shut in for 24 hours. This is 
minimum time needed for cement cure. Static pressure data or remedial gas lift valve changes can also done during this time.

\section{WSO Results}

Not all wells in Belayim Fields have required WSO work. Nevertheless, 78 rigless WSO workovers have been completed during the past 4.5 years with a technical and economic success approaching 90\%. Of the successful jobs, some withstanded a matter of weeks while others have isolated WC for several years. Length of sustained WC improvement loosely correlates with TTBP placement, vertical permeability barriers, and integrity of cement behind casing. Just below 4.8 million dollars already spent till date for almost average about 61,500 per job. Gradual initial production rates averaged 2500 bopd per job and WC's were typically reduced from $55 \%$ to $16 \%$. Based on results to date, job cost in averagespentin 1.9 days using a 13dollars per barrel for crude oil price. Field riglesswater shut offworkovers will continue for the next several years. Individual results from the 78 rigless WSO workovers were excellent. WSO work initially targeted $100 \%$ watered out perforation intervals in the M-I sand. As interzonal isolation progressed, entire layers were eventually shut off. The following case history examples use WellX1 data to illustrate results from interzonal WSO's and complete layer isolation.

\section{Well X-1 Case History}

well X-1 is a typical case history example of multiple TTBP settings that includes interzonal as well as a complete layer WSO. Results from all four rigless TTBP WSO workovers are summarized in the following subheadings. Each figure shows pre and post WSO performance, and ties to candidate selection criteria described earlier.

\section{Interpretation for well $\mathrm{X}-1$ Test data}

Well tests are the best indicator of economic WSO success. The four WSO events show:

a) A 3863 bopd incremental gain after the lower M-I perforation interval was isolated during 2June 2006.

b) A 1299 bopd gain after the lower-middle M-I interval was isolated during 27 May 2007.3) A 2633 bopd gain after the upper-middle M-I interval was isolated during11February2008.

c) A 2750 bopd gain after the top M-I interval was isolated during 30 December 2008. Even though well test data is infrequent, large incremental oil production gains and low workover costs paid out each job in about 2.0 days using a normalized price per barrels 13 dollars.lf this WSO work was not performed, expensive rig deployed WSO would have been completed.

14. Analysis for Water Cut result

Wellhead WC reflects the validity of each WSO workover. The four WSO events show:

a) A 39\% incremental reduction from 39\% to $0.2 \%$ after 2 June 2006.

b) A 37\% reduction from 38\% to $1.0 \%$ after 27 May 2007 .

c) A $39 \%$ reduction from $40 \%$ to $0.9 \%$ after 11 February 2008 .

d) A $48 \%$ reduction from $48 \%$ to $0.2 \%$ after 30 December 2008 .

As expected with interzonal WSO work, WC was reduced to low levels temporary and only to increase after few months. This was due to the absence of vertical permeability barriers within the M-1 itself. After the fourth WSO, the M-I was completely isolated because the shale between the M1 and $\mathrm{MN}$ is sealing. WC has remained less than $1.0 \%$ for the past six months. The final M-1-layer WSO is now allowing the MN to produce its tremendous reserve.

\section{TTBP Placement}

Four TTBP's were set in Well X-1 (Figure 3). In 2 June 2006 TTBP was set at 11,950 feet over the bottom M-l perforation intervals and capped with 14 feet of cement. Eight feet of shale isolate thatinterzonal WSO from the rest of the M-1 perforations above.In 27 May 2006 TTBP was set at 11,898 feet and capped with 16 feet of cement. Un presence of a vertical permeability barrier was suspected as the reason for the quick WC increase. As a result, in 11 February 2008 TTBP was set at 11,858 feet and capped with 13 feet of cement. Only 4 feet of shale isolated M-l perforations from the top set.The final M-1TTBP was set on 30 December 2008 at 11,814 feet and capped with 13 feet of cement. Over 30 feet of shale caps the M-1 at this location. Therefore, water has been shut 
off and WC suppressed for the past six months at less than $1 \%$. Well X-1 was not considered a terminal producing well, but each zone was at or near $100 \%$ WC before completing WSO work.

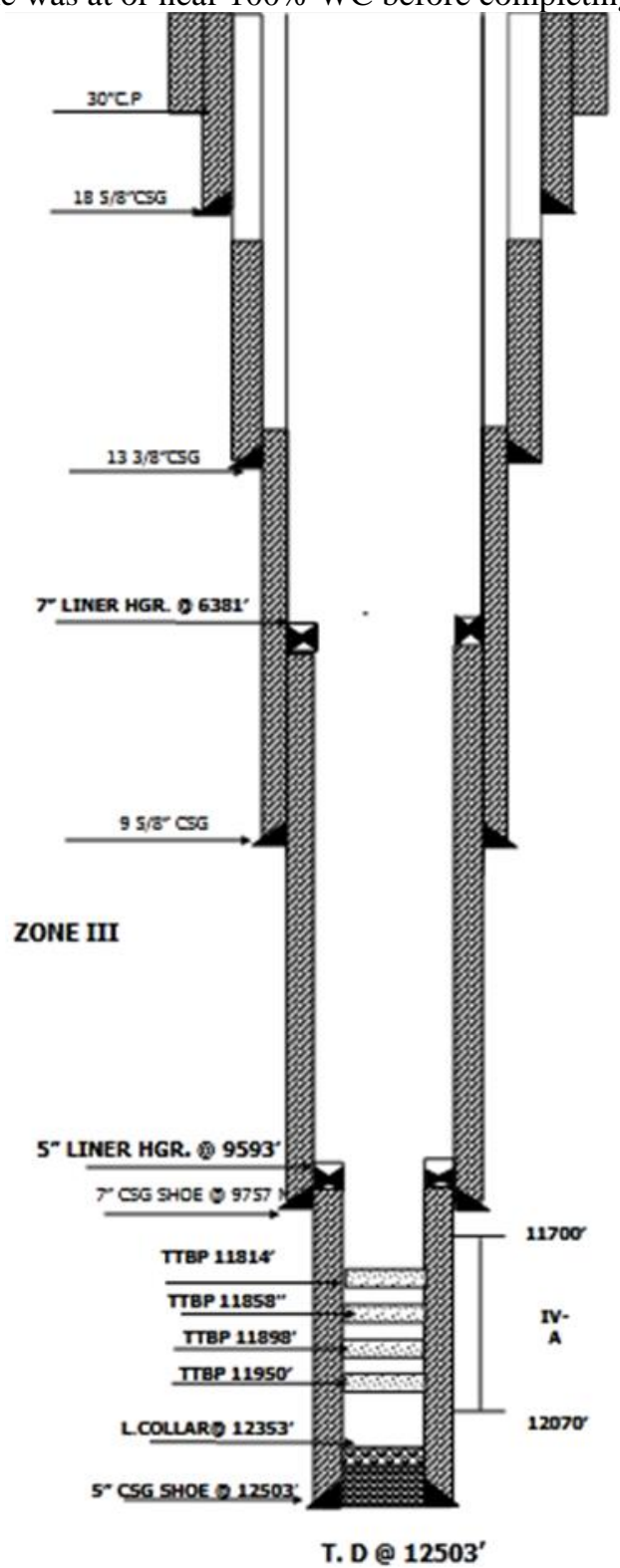

Fig. (3) - Well X-1 TTBP Placement sketch

\section{Future Challenges}

Based on the successful results achieved to date, Belayim Field rigless WSO workover program is recommended and will continue for several years. Future challenges include:

a) Improving and expanding success of the higher risk interperforation TTBP WSO to maximize oil recovery.

b) Clarifying water hold up affecting PLT calculations.

c) Defining water movement through the lower quality TZ sand layer.

d) Balancing future WSO workovers with water injection.

17. Conclusions

a) Through Tubing Bridge Plug (TTBP) jobs done successfully and economically on a big scale to minimize theproduced water. $65 \%$ successfulpercentagereachedthrough usingthat technique.

b) An average 2500 bopd incremental gain, 39\% WC reduction, and 1.9 day payout were achieved by 78 rigless TTBP WSO workovers. 
c) Rigless WSO workovers have become a significant reservoir management tool to maximize field rate above 150,000 bopd and optimize 135 mmcfd oflift gas.

d) TTBP WSO workovers are only $12 \%$ of the cost of rig deployed WSO work and vital for cost control as the field matures.

e) Recovery within a perforation interval can be improved by using interperforation WSO's.

\section{References}

1. M. A. Farooqui, Y. A. A1-Rufaie: "Rigless Techniques Enhance the Effectiveness and Economics of Water Shut-Off Treatments," paper SPE 39511 presented at the SPE India Oil and Gas Conference and Exhibition held In New Delhi, India, February 17-19, 1998.

2. Joseph, A.; Ajienka, J.A. A Review of Water ShutoffTreatment Strategies in Oil Fields.Presented at theAnnual SPE International Conference and Exhibition, Tinapa-Calaber, Nigeria, 31 July-7 August 2010.

3. PATEL, C. N., \&Kishori, M. S. (2016). Analytical and Software Based Comparative Analysis of on Ground Circular Water Tank. International Journal of Civil Engineering (IJCE), 5 (3).

4. M.A. Mohammed, M.A. A1-Mubarak, A.K. A1-Mulhim, S.M. A1-Mubarak, and A.A. A1Safi: "Overview of Field Results Using TTBP as Effective Water Shut-Off Treatment in Openhole Well Completions in Saudi Arabia," paper SPE 39616 presented at the SPE/DOE Improved Oil Recovery Symposium held in Tulsa, Oklahoma, April 19-22, 1998.

5. Narendra, S., \&Daketi, S. (2016). Water as Element in Architecture. BEST: International Journal of Management, Information Technology and Engineering (BEST: IJMITE), 4(1), 49-60.

6. Mahmoud A. Fotuh, and SamehMacary: "Factors That Affect the Success of Mechanical Water Shut-off in Wells," paper SPE 62891 presented at the SPE Annual Technical Conference and Exhibition held in Dallas, Texas, October 1-4, 2000.

7. Makki A. AL-Zubail, Redha H. Al-Nasser, Saleh A. Al-Umran, Saeed S. Al-Saeed: "Rigless Water Shutoff Experience in Offshore Saudi Arabia," paper SPE 81443 presented at the SPE 13th Middle East Oil Show \& Conference held in Bahrain April 5-8, 2003.

8. Fahad A. Al-Ajmi, Ali M. Al-Shahri, Mustafa M. Sengul, and Robert Phelps: "Evaluation of Super-K Wells Performance Using Fluid Flow Index in Ghawar Field," paper SPE 68162 presented at the SPE Middle East Oil Show held in Bahrain, March 17-20, 2001.

9. NDUKA, A. O. INNOVATION IN A WATER WELL POTABLE DRILLING MACHINE DESIGN ANALYSIS.

10. S. Chan: "Water Control Diagnostic Plots," paper SPE 30775 presented at the SPE Annual Technical Conference \& Exhibition held in Dallas, USA, 22-25 October, 1995.

11. B.J. Rouser, Y.A. Al-Askar, T.H. Hassoun: "Monitoring Sweep in Peripheral Waterflood: A Case History," paper SPE 21372 presented at the SPE Middle East Oil Show held in Bahrain, November 16-19, 1991.

12. Li, J., \& Li, H. (2019).Numerical Simulation of Water Wave Based on Chebyshev Spectral Method. International Journal of Applied and Natural Sciences, 8, 153-160.

13. .Khalaf, F: "Optimizing Operations Significantly Reduced Drilling Time and Cost in Gulf of Suez, October Field", SPE paper 15695 presented at the 5th SPE Middle East Oil Show held in Manama, Bahrain, 7-10 March 1987.

14. Hassan, I. et.al.: "Slim-Hole Drilling and Innovation Enable the Development of the October Nezzazat, A Marginal Field in Egypt", SPE paper 29828 presented at the SPE Middle East Oil Show, Bahrain, 11-14 March 1995.

15. Korotkova, T. G., Danilchenko, A. S., \&Sedoy, Y. N. (2019).Evaporation Rate of Water from Glass Surface under Natural and Forced Convection. International Journal of Mechanical and Production Engineering Research and Development, 9(4), 955-962.

16. Amoco Exploration and Production Company internal exploitation and petrophysics study for the October Field dated July 1987.

17. Leggett, R.B. et.al.: "Multi-Phase Flow Meter Successfully Measures 3-Phase Flow at Extremely High Gas Volume Fractions - Gulf of Suez, Egypt", SPE paper 37837 presented at the SPE European Petroleum Conference held in Milan, Italy, 22-24 October 1996.

18. Gunther, M.: Schlumberger service center in RasShukheir, Egypt; personal conversation.

19. Bakieva, A. N. A. R., Akimov, M. U. K. H. A. M. E. D. Z. H. A. N., Abdilova, G. A. L. I. Y. A., Ibragimov, N., \&Bekeshova, G. (2019). Developing new type of disk plate for meat chopper and its effect to water-binding capacity and yield stress of minced 
meat. International Journal of Mechanical and Production Engineering Research and Development, 9(6), 377-390.

20. Mansour,S. et.al.: "Optimized Completion Significantly Reduced Cost and Time in Gulf of Suez", SPE paper 17984 presented at the SPE Middle East Oil Technical Conference and Exhibition held in Manama, Bahrain, 11-14 March 1989. 